Paidéia, 2006, 16(35), 427-436

\title{
PROCESSOS DE RESILIÊNCIA NO CONTEXTO DE HOSPITALIZAÇÃO: UM ESTUDO DE CASO ${ }^{1}$
}

\author{
Daniela Cristina Silva Bianchini \\ Universidade do Vale do Itajaí \\ Débora Dalbosco Dell'Aglio \\ Universidade Federal Rio Grande do Sul
}

\begin{abstract}
Resumo: Este trabalho apresenta uma revisão teórica e uma discussão crítica, a partir de um caso clínico, sobre o conceito de resiliência no contexto de hospitalização. A revisão bibliográfica foi realizada nas bases de dados Scielo e BVS-Psi. A resiliência, vista como a capacidade do indivíduo para enfrentar situações de risco de forma saudável, apresentando respostas adaptativas frente a adversidades, é um importante conceito a ser compreendido pelos profissionais que atuam na saúde. Analisar as diferentes formas apresentadas por pacientes para lidar com a doença, durante o período de internação em hospitais gerais, permite uma melhor compreensão das condições facilitadoras da resiliência e abre possibilidades para trabalhos de prevenção e promoção de saúde nestas instituições.
\end{abstract}

Palavras-chave: Resiliência; Hospitalização; Risco.

\section{RESILIENCE PROCESS IN THE HOSPITALIZATION CONTEXT: A CASE STUDY}

Abstract: This article presents a theoretical revision and a critical discussion, from a clinical case, about resilience concept in the hospitalization context. Scielo and BVS-Psi based the literature review. Resilience, as individual capacity to face risk situations in a healthy way, presenting adaptive answers to adversities, it is an important concept to be understood by health professionals. Analyzing sickness during hospitalization period in general hospitals, allows a better understanding of facilitating conditions to resilience and open possibilities for prevention work and health promotion in these institutions.

Key words: Resilience; Hospitalization; Risk.

O interesse na compreensão dos processos de bem-estar e qualidade de vida emocional vem ganhando espaço nas discussões no campo da Psicologia. Esta perspectiva é defendida pela Psicologia Positiva e busca uma compreensão do indivíduo a partir de seus potenciais, motivações e capacidades, rompendo com a tendência de perceber o ser humano dentro da abordagem reducionista da psicopatologia (Sheldon \& King, 2001). O estudo da resiliência em instituições de saúde, especialmente em situação de hospitalização, pretende compreender que características individuais e ambientais podem ser modificadas ou estimuladas para que os indivíduos apresen-

\footnotetext{
${ }^{1}$ Recebido em 05/10/2006 e aceito para publicação em 26/02/2007 ${ }^{2}$ Endereço para correspondência : Débora Dalbosco Dell'Aglio, Instituto de Psicologia/UFRGS, Programa de Pós-Graduação em Psicologia. Rua Ramiro Barcelos, 2600/115, Porto Alegre, RS, CEP: 90035-003, E-mail: dalbosco@cpovo.net
}

tem estratégias eficazes de enfrentamento de situações adversas. Dessa forma, o objetivo deste estudo foi compreender o processo de resiliência no ambiente hospitalar, a partir de uma integração entre aspectos teóricos e a análise de um caso clínico de uma paciente acompanhada em um hospital geral.

A Psicologia Positiva vem se fortalecendo nos últimos anos e alguns autores, como Rutter (1993), fazem uma crítica à tendência limitante do estudo baseado no sofrimento, afirmando que apesar da Psicologia procurar entender como os indivíduos sobrevivem em situações de adversidade, muito pouco se sabe sobre como pessoas normais se desenvolvem em condições mais saudáveis. A partir da década de setenta, a prática clínica da Psicologia estava começando a sair do modelo centrado no tratamento de distúrbios para começar a visualizar a importância da clínica preventiva (Yamamoto, 2005). Dentro deste 
contexto, a Psicologia Positiva vem se preocupando com o estudo de fenômenos psicológicos como a felicidade, altruísmo e satisfação (Yunes, 2003).

A idéia de demarcar uma estrutura para este novo conceito dentro da Psicologia é proposta por Seligman e Csikszentmihalyi (2000), visando à experiência subjetiva positiva do ser humano. Eles defendem a idéia de que o trabalho de prevenção deve criar uma nova ciência da força humana, na qual a missão será entender e aprender como promover virtudes, como coragem, otimismo, habilidades interpessoais, entre outras.

Sheldon e King (2001) também enfatizam a importância dos psicólogos adotarem uma perspectiva referente aos potenciais humanos, motivações e capacidades. Lampropoulos (2001) propõe que tratamentos profissionais incluam fatores terapêuticos como: expectativa positiva e esperança do paciente quanto à mudança, senso de otimismo e defesas adaptativas. Intervenções que enfatizam características positivas e fortalecedoras do ser humano deveriam estar inseridas nos tratamentos profissionais, como, em instituições de saúde, devido à capacidade de reduzir sintomas e prevenir recaídas, aumentando conseqüentemente a qualidade de vida (Giacomoni, 2002). A busca pelos fatores terapêuticos citados, passa a ser então, um dos novos desafios para instituições de saúde nas próximas décadas.

\section{Resiliência}

O tema da resiliência dentro da psicologia ainda é relativamente recente, porém sua relevância frente ao estudo do desenvolvimento humano vem crescendo. $\mathrm{O}$ processo de resiliência refere-se à classe de fenômenos caracterizada por bons resultados apesar de sérias ameaças à adaptação ou ao desenvolvimento (Yunes, 2003). O significado da resiliência está relacionado com processos psicossociais, que favorecem o desenvolvimento sadio do indivíduo, mesmo quando este se encontra frente a adversidades e problemas. Muitos autores citam o termo flexibilidade interna para manejar dificuldades e conseguir re-significar sua vida (Pinheiro, 2004; Yunes \& Szymanski, 2001), traçando seu caminho através de saídas não depressivas. A resiliência, neste sentido, refere-se a processos que operam na presença do risco para produzir características saudáveis, e não para evitar ou eliminar fatores de risco (Morais \& Koller, 2004).

Masten (2001) afirma que os caminhos trilhados para a compreensão da resiliência levaram investigadores a estudos integrados sobre sistemas adaptativos no desenvolvimento humano, e como estes se desenvolvem e respondem a variações no meio ambiente. A autora diz que é necessário compreender os fenômenos da resiliência através de seus processos em múltiplos níveis, de genes a relacionamentos, e investigar como um indivíduo,um complexo sistema vivo, pode interagir efetivamente ao longo do tempo onde está inserido.

Para Masten (2001), a resiliência mostra-se um fenômeno comum, ao invés de surgir de processos extraordinários, oferecendo um olhar mais positivo do desenvolvimento e adaptação dos seres humanos, bem como direções para práticas que objetivam a melhora de pessoas em risco. Se os sistemas de proteção do indivíduo estão em bom funcionamento, o desenvolvimento é forte mesmo frente à severa adversidade; se este sistema principal está deteriorado, antes ou em consequiência da adversidade, então o risco de problemas é muito maior, particularmente se os do ambiente são prolongados. Assim, o estudo de fatores que levam à resiliência direciona, segundo Masten (2001), para uma ciência integrada de adaptação e desenvolvimento humano.

Outro autor que também buscou o conhecimento por processos adaptativos dos seres humanos foi Simon (1989), que criou a teoria da adaptação, que significa o conjunto de respostas de um organismo vivo, em vários momentos, a situações que o modificam, permitindo manutenção de sua organização (por mínima que seja), compatível com a vida. O organismo, na busca pela adaptação, integra da forma mais adequada possível os sistemas afetivo, intelectual, conativo e anatomofisiológico, sendo que a eficácia deste processo varia de uma pessoa a outra, e em uma mesma, dependendo das circunstâncias internas e externas que a rodeiam.

Morais e Koller (2004) colocam que a resiliência é entendida como uma reafirmação da capacidade humana em superar adversidades, mas que isto não significa dizer que o indivíduo saia da crise ileso, como implica o termo invulnerabilidade. 
Estas autoras também defendem a idéia de que as bases da resiliência apresentam-se tanto constitucionais quanto ambientais, o que significa que não existe, por conseguinte, uma quantidade fixa de processos de resiliência em um indivíduo, e sim, que o modo saudável de enfrentar crises pode variar de acordo com as circunstâncias. A resiliência é entendida, portanto, não como uma característica do indivíduo ou como uma capacidade inata, herdada por alguns "privilegiados", mas a partir da interação dinâmica existente entre as características individuais e a complexidade do contexto social, entre as herdadas geneticamente e as pessoais desenvolvidas ao longo do ciclo vital e da sua relação com o ambiente social (Morais \& Koller, 2004).

\section{Fatores de risco e proteção}

Para a compreensão dos mecanismos facilitadores dos processos de resiliência, através da observação da interação entre as características individuais e ambientais, torna-se essencial a identificação de fatores de risco e particularmente os de proteção, tanto pessoais como interpessoais (Pereira, 2001). Esta relação entre estes fatores de risco e proteção é um aspecto necessário para se chegar ao conceito de resiliência, sendo importante destacar o binômio risco-proteção (Pinheiro, 2004).

O conceito de risco está diretamente relacionado com eventos negativos de vida, que, quando presentes, aumentam a probabilidade de o indivíduo apresentar problemas (Yunes \& Szymanski, 2001). Ao se encontrar diante de adversidades, muitas vezes causadoras de estresse ou trauma, o indivíduo se torna suscetível à vulnerabilidade e ao desequilíbrio (Rodrigues \& Gasparine, 1992). Entre alguns dos fatores de risco, pode-se citar a desorganização familiar, perdas precoces significativas, violências física e psicológica, doenças, entre outras (Trombeta \& Guzzo, 2002; Yunes \& Szymanski, 2001). Contudo, Yunes e Szymanski (2001) afirmam que o conceito de risco deve ser sempre pensado como processo e não como variável em si, não sendo assumido a priori, visto que estes fatores se constituirão em risco ou não, dependendo do comportamento que se tem em mente e dos mecanismos pelos quais operam seus efeitos negativos no homem. Para as autoras, é relevante compreender quais os significados dos riscos que são flutuantes na história das pessoas, ou seja, quais mudam de acordo com as circunstâncias de vida e têm diferentes repercussões.

Pesce, Assis, Santos e Oliveira (2004) também ressaltam a importância de se compreender as circunstâncias em que o indivíduo se encontra para se avaliar o conceito de risco. Para estes autores, os eventos negativos de vida são considerados fatores de risco, pois podem impor um sofrimento estagnador, que impede ou dificulta a capacidade de seguir em frente. No entanto, esses eventos negativos podem também, em certos momentos, permitir uma reorganização da vida e vontade de seguir em frente.

Assim como o estudo dos conceitos de risco mostra-se relevante para o entendimento do desenvolvimento humano, estudar características protetoras que se desenvolvem e que podem modificar o percurso pessoal do indivíduo também é essencial (Rutter, 1993). Os fatores de proteção (usualmente chamados de mediadores - buffers) serão aqueles que, numa trajetória de risco, acabam por mudar o curso da vida da pessoa para um "final feliz" (Yunes \& Szymanski, 2001); eles estão diretamente associados ao desenvolvimento saudável e relacionam-se a: 1) aspectos individuais, como auto-estima positiva, autocontrole, autonomia, orientação social positiva; 2)familiares, como famílias coesas, estabilidade, respeito; e 3) fatores do meio ambiente em que o indivíduo se insere, como relacionamentos saudáveis com colegas, professores, e outras redes de apoio disponíveis (Pesce \& cols., 2004; Yunes \& Szymanski, 2001).

Pereira (2001) cita estudos de tipos de personalidade particularmente resistentes ao estresse, que são geralmente autoconfiantes, acreditam em si e naquilo que pretendem fazer, e revelam percepção de controle sobre o que lhes acontece. A autora também salienta que são indivíduos que gostam e aceitam as mudanças e encaram as situações de estresse como desafios, sendo-lhes, portanto, possível crescer frente às adversidades. Personalidades com locus de controle interno, extrovertidas, emocionalmente estáveis, com elevado autoconceito e boa auto-estima, são as que funcionam de maneira a minimizar os fatores de estresse. Por outro lado, as do tipo A, com locus de controle externo, procrastinadoras e catastrofizantes, são propensas a maiores riscos e estresse (Pereira, 2001). 
Morais e Koller (2004) analisam os processos sadios do ser humano a partir da Abordagem Ecológica do Desenvolvimento Humano, em que a pessoa é vista a partir das suas características biopsicológicas e das construídas na interação com o ambiente. As autoras as dividem em três núcleos diferentes: características de disposição; recursos biopsicológicos e demandas. As características de disposição referem-se a atributos pessoais que podem promover $\mathrm{o}$ desenvolvimento (forças generativas) bem como retardar ou mesmo impedi-lo (forças disruptivas): curiosidade, elevado nível de auto-eficácia e responsividade são exemplos de forças generativas e impulsividade, distração e baixo nível de auto-eficácia ilustram as forças disruptivas; já as características de recursos biopsicológicos envolvem as deficiências (defeitos genéticos, baixo peso no nascimento, deficiência física ou mental) ou atributos psicológicos (capacidades, habilidades e conhecimentos que evoluíram ao longo do desenvolvimento) que influenciam a capacidade da pessoa de se engajar de forma efetiva nos processos proximais; as características de demanda dizem respeito aos atributos pessoais (inatos ou não) capazes de estimular ou desencorajar as reações do ambiente social, como por exemplo, gênero, etnia, temperamento, e aparência física atrativa versus não atrativa.

Portanto, como já salientado, os estudos e conseqüentemente a compreensão das características do indivíduo, bem como dos fatores de risco e proteção que o mesmo enfrenta no decorrer da vida, parecem ser o caminho mais eficaz para explicar os processos de resiliência nos seres humanos e como o desenvolvimento pode se tornar mais saudável.

\section{Resiliência em situação de doença}

Pensa-se em indivíduos que apresentam resiliência frente às mais variadas situações problemáticas, mas quer-se destacar aqui a doença como a principal delas. A resiliência, neste contexto, seria a capacidade de um indivíduo lidar com a doença, aceitando suas limitações, colaborando com aderência ao tratamento, readaptando-se e sobrevivendo de forma positiva.

A ciência e a tecnologia cada vez mais possibilitam o diagnóstico precoce e a terapêutica adequada das doenças, permitindo sua evolução e até mes- mo a cura. Porém, mesmo com tais avanços, muitas moléstias promovem alterações orgânicas, emocionais e sociais, que exigem constantes cuidados e, conseqüentemente, processos adaptativos. Morais e Koller (2004) dizem que todas as experiências individuais negativas de vida estarão sendo influenciadas pela forma como essa pessoa já experimentou (ou não), no seu passado, esses fenômenos, e também como esta situação é percebida historicamente e no momento atual.

Camon (2003) discute as implicações do imaginário no processo de hospitalização. Para o autor, ela é agravada mais por conceitos apriorísticos do indivíduo do que por ela mesma. Mais importante do que buscar na patologia que determinou a hospitalização a decorrência do sofrimento vivido pelo paciente é a análise dos fatores subjetivos que marcam a própria conceituação de enfermidade, e por assim dizer, o nível deste sofrimento. Ou seja, quanto menos autoconfiança, esperança e vontade de vencer o paciente apresentar, maior será o grau de prejuízo para o mesmo.

Romano (1999) também defende a importância do estudo da estrutura prévia de cada indivíduo. Assim, as diferentes formas de reação psicopatológica decorrem em função de distúrbios de comportamentos estruturados em uma personalidade predisposta a reações mais ou menos fixas, refletindo o potencial adaptativo ou não do enfermo. O psíquico é resultante de vetores como a estrutura da personalidade, interpretação e vivência dos acontecimentos, considerando aspectos do imaginário e do real.

Este novo olhar humanizado permite perceber que o paciente, ao chegar ao hospital, traz consigo, além da doença, sua história de vida. Portanto, segundo Camon (2003), é pertinente reafirmar que o agravamento de determinados processos da hospitalização pode acabar se dando mais no imaginário do paciente. Dessa forma, as condições emocionais é que determinarão uma parcela bastante significativa no processo de sua recuperação, não apenas pelo seu desejo de cura e superação da hospitalização em si, mas principalmente pela maneira como a doença foi configurada e sedimentada em seu imaginário.

Porém, a hospitalização também pode ser entendida como um fator de risco no desenvolvimento 
do indivíduo. Ao chegar no hospital, o paciente se vê impelido a enfrentar uma série de mudanças bruscas no seu dia a dia. A interrupção de sua rotina; a separação do que lhe é familiar e do que lhe traz segurança (casa, pertences, parentes e amigos, trabalho); a submissão a uma equipe de profissionais muitas vezes desconhecidos e a acomodações geralmente desconfortáveis; a possibilidade de dividir o quarto com outro paciente; além da dor física, são alguns dos fatores de risco aos quais o indivíduo se encontra exposto (Camon, 2003; Romano, 1999). Se o diagnóstico for o de doença crônica, as repetidas internações e o estigma de doente incurável podem agravar ainda mais o quadro do paciente. Pesce e cols. (2004) citam que pacientes que se encontram expostos à adversidade crônica podem apresentar efeitos negativos no desenvolvimento, como sequielas emocionais posteriores, que em geral não aparecem em pacientes que passam por rápida internação.

Na rotina hospitalar, podem ser observadas diferentes formas de o indivíduo reagir à situação de internação. Para preservar o ego de situações que ameacem sua integridade, o paciente pode recorrer a mecanismos de defesa, como a negação, regressão e isolamento, não raro comprometendo sua relação com o tratamento e até mesmo agravando seu estado clínico (Fongaro \& Sebastiani, 2003). Contudo, ele também pode encontrar recursos positivos de enfrentamento da situação de hospitalização, se reorganizando frente à doença e internação, e enfrentando os episódios específicos do processo de tratamento.

Além das características pessoais dos pacientes, que muitas vezes podem determinar processos de resiliência frente à hospitalização, também se mostram importantes algumas estratégias utilizadas dentro do hospital para facilitar o desencadeamento de tais processos. O estabelecimento de boas relações médico-paciente, a humanização no atendimento, o fornecimento de informações claras e compreensíveis aos pacientes, dentro de um programa multiprofissional, são algumas delas. Para Romano (1999), conhecer sua verdadeira condição facilita ao paciente dissipar seu medo e fantasias, reforçando sentimentos de cooperação, confiança e esperança, fatores protetores à saúde humana.
Contudo, uma doença nunca é a mesma para diferentes pessoas; ela não é única em suas manifestações e igualmente provoca reações singulares em cada paciente, que também é diferente e único (Camon, 2003). Na busca de maior compreensão sobre estas diferentes formas de lidar com a doença, procura-se discutir os processos de resiliência, que podem ser observados em situação de hospitalização, através da apresentação de um estudo de caso.

\section{Descrição do caso clínico}

Relata-se aqui o caso de S.M., paciente do sexo feminino, com 59 anos de idade, divorciada, mãe de dois filhos, residente do interior do estado do Rio Grande do Sul, apresentando diagnóstico clínico de Pênfigo Vulgar. Esta internação hospitalar em uma unidade de internação geral, pelo SUS, ocorreu por um período de três meses e meio, tendo sido esta, a sua terceira pelo mesmo diagnóstico. O início da doença se deu há cinco anos, sendo que a paciente não relacionava a primeira crise com alguma situação especial que tivesse vivenciado; ela foi atendida pelo Setor de Psicologia de um hospital público da cidade de Porto Alegre, Rio Grande do Sul, desde o segundo dia de internação até sua alta hospitalar, sendo as entrevistas realizadas num quarto de isolamento, onde estava internada.

$\mathrm{O}$ pedido de atendimento foi feito pelo residente de medicina interna responsável pela paciente; nele não constavam os sintomas psíquicos apresentados por S.M., percebendo-se mais tarde que a decisão do médico em solicitar a consultoria era devido também a uma ansiedade da equipe frente ao diagnóstico. A partir da primeira entrevista, estabeleceuse, em conjunto com a paciente, um plano de atendimento de três vezes semanais até sua alta hospitalar.

A doença do pênfigo vulgar compreende uma dermatose de etiologia desconhecida, sendo uma auto-imune, que gera anticorpos contra uma proteína essencial para adesão das células da pele. Apresenta-se na forma de lesões cutâneas bolhosas, que podem se romper rapidamente, formando ulcerações dolorosas por toda a pele. Se não tratada pode evoluir para desnudamento intenso, levando a desequilíbrio hidroeletrolítico, sepsis e óbito (Aoki, 2004).

$\mathrm{Na}$ primeira entrevista, a paciente encontrava-se deitada na cama, nua, com bolhas por todo o 


\section{Daniela Cristina Silva Bianchini}

corpo, apresentando fraqueza e sonolência devido à medicação. Logo que a psicóloga entrou e se apresentou, a mesma agradeceu pela presença e começou a mostrar as bolhas espalhadas pelo corpo, explicando que estava nua, pois nem mesmo um lençol poderia tocar em seu corpo. Se pegar o lençol ou qualquer roupinha, mesmo que leve, queima tudo. Como as bolhas estão na fase de estourar, a agonia é muito grande, queima e coça sem parar. Tive que vir da minha cidade, que fica no interior, até aqui, no carro do meu filho pelada (sic).

Nesta primeira sessão, a paciente conseguiu expressar claramente a angústia que a doença lhe causava, a dor que sentia, bem como as fantasias relativas à imagem corporal. Porém, ao mesmo tempo em que relatou sonhos com seu corpo deformado, acreditava que dentro de alguns meses a crise passaria e que sua vida retornaria a ser feliz.

Já durante os atendimentos iniciais, a paciente mostrou-se bastante aberta e interessada nas sessões psicológicas, sempre disponível para o diálogo e indicando, desde o início, vontade de superar a doença e boa capacidade de abstração. Ainda no primeiro contato, ela explicou que já era a terceira vez que precisava ser internada, e estava ciente do risco da doença e da dificuldade da medicina em compreender e curar casos como este. Sabia que provavelmente não seria a última vez que teria que ser internada e dizia estar "trabalhando em sua cabeça" que a doença seria uma companheira ruim que a acompanharia pela vida inteira.

Relatou que tinha dois filhos, frutos de seu único casamento, que havia se divorciado há sete anos. Sobre isso referiu: Na época me senti muito triste, mas a vida tem que continuar e eu tenho muitos amigos no lugar que moro, tenho também amor próprio...vamos pro bailão da terceira idade quase todos os finais de semana e eu danço sem parar. Adoro dançar e paquerar (sic).

A paciente relatou que se encontrava sozinha, sem visitas de familiares durante a internação, pois seus filhos trabalhavam em outro estado. Acreditava que eles se preocupavam com ela e que sabiam da demora para a recuperação, esperando ainda receber a visita deles durante o período hospitalar. Todas as vezes que a psicóloga entrava no quarto, S.M. mostrava-se aberta aos atendimentos, apresentando necessidade de exteriorizar seus sentimentos. Sempre reclamava que não agüentava mais ficar sem roupa, mostrando a vontade de poder se vestir e arrumar. Eu sou mais que isto (doença), eu sou uma mulher vaidosa, feliz, sempre de bom humor, preciso de vida, preciso também tomar banho, passar perfume. Desde que cheguei aqui não tomo banho (sic).

Apesar da tristeza muitas vezes demonstrada por S.M., principalmente relacionada à agonia causada pelas coceiras e ardências das bolhas, a mesma sempre colaborava com a equipe, tanto com médicos quanto com enfermeiros, e estava em busca de alternativas para passar o tempo (pediu que seus filhos trouxessem seus cds favoritos e revistas de palavras cruzadas) e para relaxar (criava momentos, como técnicas de respiração e pensamentos em momentos felizes de sua vida).

Durante os atendimentos, a psicóloga, que também mantinha contato semanal com a equipe de médicos e de enfermagem, verificava que os profissionais mostravam-se bastante ansiosos frente a uma possível queda emocional da paciente. Devido a isso, a equipe estava bastante presente no dia a dia, demonstrando paciência e solidariedade para com ela. Assim, o vínculo estabelecido entre eles foi de confiança, facilitando a empatia.

Nas evoluções registradas no prontuário, a psicóloga apontava que a paciente estava enfrentando adequadamente a situação adversa, demonstrando boa capacidade de compreensão do quadro clínico, aceitação da situação, com exame do estado mental preservado, mostrando-se coerente e dentro da realidade em seu discurso e com grande vontade de se recuperar. Durante os atendimentos, mesmo nos momentos mais críticos da internação, ela falava muito em Deus e na fé que sentia, acreditando que esta poderia salvá-la. A fé para a paciente era sinônimo de fortificação e esperança: a fé é a minha fiel companheira (sic). Também se referia ao exemplo de sua mãe, que se mostrava uma mulher guerreira, que lhe ensinou a ter força e fé nos momentos de dificuldade. Muitas vezes, ela exibia preocupação com seu futuro, chorava e sentia medo em relação à doença; mas também fazia planos, acreditando sempre que viver valia a pena. 
Com o passar das semanas, as bolhas foram estourando e secando, permitindo que a paciente pudesse ser coberta com um lençol, sentar na cama. Em seguida, S.M. pode, pela primeira vez durante a internação, tomar banho. Assim, ao entrar no quarto, a psicóloga se deparou com a paciente de vestido, sandálias, com batom, perfumada, usando anel e brincos, pintando as unhas de vermelho. Não falei que aquela deitada na cama não era eu? Pois bem, eu estou aqui ó, com vida novamente. Esta doença não vai me derrubar. Sabia que iria melhorar e antes de vir para o hospital me certifiquei que meu filho havia colocado na mala, minhas coisinhas de embelezar! Gosto de mim assim, bonita e feliz (sic). Neste dia, S.M. tinha sido liberada pela primeira vez para se vestir, pois não havia mais risco de infecção. Este era um momento pelo qual ela esperava há bastante tempo, pois relatava à equipe o desejo em poder se arrumar.

No período seguinte, S.M. continuou apresentando estratégias positivas para enfrentar a situação: observou-se uma constante busca de informações com a equipe; adesão ao atendimento psicológico; vontade em auxiliar a equipe nos procedimentos como banho, troca de curativos; disposição para arrumar seu quarto; e vínculo afetivo estabelecido com os técnicos do hospital, demonstrando capacidade de adaptação.

\section{Discussão}

Diversos autores têm salientado a importância da compreensão do desenvolvimento humano como resultado da interação das características constitucionais da pessoa e do seu ambiente (Ismael, 2005; Romano, 1999). Assim, observa-se maior ênfase nos fatores de proteção que modificam, melhoram ou alteram respostas pessoais a determinados riscos de desadaptação, tendo em vista a saúde como um processo e não um estado absoluto.

Fica cada vez mais claro que o funcionamento normal do ser humano não pode ser contado apenas pelos quadros de referência puramente negativos ou focados em problemas (Sheldon \& King, 2001). Dessa forma, a partir do referencial da Psicologia Positiva e do conceito de resiliência, podem-se compreender as características apresentadas por S.M., no decorrer de sua internação, como aspectos relevantes de enfrentamento saudável.

S.M. encontrava-se em uma situação que poderia se constituir em risco para seu bem-estar: apresentava uma doença rara e de tratamento difícil, estava internada em um hospital público (sem a possibilidade de recorrer a atendimento privado de saúde), não contava com apoio de pessoas próximas ou familiares, apresentava um quadro de doença crônica e incurável, que exigia longos períodos de observação, controle e cuidados. Então, que processos, na natureza do funcionamento desta paciente, foram utilizados para que a mesma conseguisse sucesso na adaptação à nova realidade? Quais os fatores que a levaram a apresentar habilidades para enfrentar de forma saudável a situação?

Certamente existiam fatores de proteção que se faziam presentes, como: auto-estima elevada gosto de mim assim, bonita e feliz; sou mais do que isto (doença); tenho amor próprio (sic); alta tolerância à frustração - esta doença não vai me derrubar (sic); orientação social positiva - visão da mãe como mulher forte e guerreira, que lhe ensinou a ter esperança e fé; e crença em Deus - fé como fiel escudeira (sic). Características pessoais positivas, como autonomia, auto-estima e orientação social positiva, são apontadas como fatores que favorecem os processos de resiliência (Masten \& Garmezy, 1985). Entre outros fatores, a busca de apoio religioso também tem sido colocada como importante recurso frente a situações estressantes (Beresford, 1994) e identificada em vários estudos sobre crenças de mães de filhos portadores de enfermidade crônica, sendo considerado como um recurso importante que permite aos pais gerarem suas próprias expectativas para os eventos futuros ao longo das prestações de cuidados ao filho (Fewell, 1986; Libow, 1989). Deste modo, pode-se compreender que a crença religiosa apresentada pela paciente, adicionada às características positivas de personalidade e ao bom nível de suporte formal e institucional percebidos por ela em relação ao hospital, exerceu importante função no processo de superação de seu quadro.

Outros fatores de apoio presentes neste caso, além das características pessoais da paciente, podem ter colaborado para que a mesma pudesse apresen- 


\section{Daniela Cristina Silva Bianchini}

tar recursos positivos de enfrentamento da situação. Durante os atendimentos, ela sempre se referia a seus familiares, especialmente seus filhos, e citava constantemente a importância dos amigos em sua vida. Para Giacomini e Galvan (2005), a família exerce um papel fundamental no processo de hospitalização, através do apoio emocional, acolhimento e incentivo, tornando-se muitas vezes determinante no prognóstico do tratamento.

A boa interação com a equipe, que se mostrou bastante interessada no caso, também pode ter auxiliado positivamente na esperança para sair deste momento de crise. A percepção positiva da paciente quanto ao hospital em que se encontrava internada, reconhecido no estado como uma instituição referência, seria auxílio na segurança que a mesma demonstrava durante o tratamento. O fato de já ter sido internada anteriormente, e por isso estar mais familiarizada com a doença e os procedimentos da internação, seria outro fator de apoio. $\mathrm{O}$ atendimento psicológico contínuo durante toda a internação também pode ser percebido como importante suporte para a paciente reagir à doença. A prática da psicologia no hospital tem mostrado que os pacientes reagem de modo favorável a esta proposta de intervenção, reconhecendo-a como necessária para sua reestruturação emocional. Assim, pode-se observar que, durante o processo de internação, o olhar orgânico por si só não é suficiente (Romano, 1999). A relação entre profissional de saúde e paciente pressupõe a necessidade de confiança dele no profissional que o atende, sendo que a formação deste vínculo de confiança não é só importante como necessária para que o "cuidado" seja possível (Gobbetti \& Cohen, 2005).

\section{Considerações finais}

No decorrer deste estudo, torna-se clara a importância da compreensão dos processos de resiliência, incluindo os fatores de proteção e risco, para o trabalho de prevenção e promoção da saúde em instituições hospitalares. Contudo, ao mesmo tempo em que se percebe seu valioso potencial, é possível constatar o quanto permeado de incertezas e controvérsias ainda se encontra este tema. Por isto, as pesquisas em busca de novas respostas sobre formas saudáveis de enfrentar situações adversas constituem-se em um grande desafio para os pesquisadores nos próximos anos.

A psicologia ainda sabe relativamente pouco sobre o sucesso humano e como encorajá-lo. A necessidade de se adotar uma perspectiva que compreenda o homem a partir de uma visão mais apreciativa, que valorize as emoções positivas, torna-se evidente. Segundo Sheldon e King (2001), as emoções positivas facilitam a criação de habilidades e recursos importantes para o indivíduo. Assim, a descrição do caso de S.M. possibilita uma reflexão sobre os processos de enfrentamento de pacientes em situação de hospitalização. Durante o período de acompanhamento desta paciente, observou-se a presença de emoções positivas por parte dela, das quais falam Sheldon e King (2001), e de fatores de proteção, a que se referem diferentes autores como Yunes e Szymanski (2001) e Pesce e cols.(2004). Aspectos individuais, como auto-estima positiva, autocontrole, autonomia, características de comportamento afetuoso; relacionamento saudável com a equipe; curiosidade e também conhecimento sobre o que estava acontecendo com sua saúde; e responsividade na aderência ao tratamento foram as estratégias apresentadas pela paciente, confirmando os fatores de proteção apontados na literatura (Pesce \& cols.,2004; Yunes \& Szymanski, 2001).

Dessa forma, fazem-se necessários novos estudos que favoreçam maior compreensão sobre as capacidades adaptativas do ser humano, podendo colaborar com o sistema hospitalar, onde é preciso criar novos espaços para se pensar na saúde, prioritariamente à doença. Além disso, é importante que se possa pensar em estratégias para a promoção de processos de resiliência no ambiente hospitalar, favorecendo circunstâncias geradoras de enfrentamento das adversidades e incrementando os fatores de proteção.

\section{Referências}

Aoki, V. (2004). Endemic pemphigus foliaceus (fogo selvagem) and pemphigus vulgaris: Immunoglobulin $\mathrm{G}$ heterogeneity detected by indirect immunofluorescence. Revista do Hospital de Clínicas, 59 (5), 251-256. 
Beresford, B. A. (1994). Resources and strategies: How parents cope with the care of a disable child. Journal of Child Psychology and Psychiatry, 35, 171-209.

Camon, V. A. A. (2003). E a psicologia entrou no hospital. São Paulo: Pioneira Thomson Learning.

Fewell, R. (1986). Support from religious organizations and personal beliefs. In R. Fewell \& P. Vadasi (Eds.), Families of handicapped children: Needs and supports across the life span (pp. 112123). Texas: Pro-Ed.

Fongaro, M. L. H., \& Sebastiani, R. W. (2003). Roteiro de avaliação psicológica aplicada ao hospital geral. Em V. A. A. Camon (Org.), E a psicologia entrou no hospital (pp. 05-68). São Paulo: Pioneira Thomson Learning.

Giacomini, M., \& Galvan, G. (2005). A atuação do psicólogo no contexto hospitalar com pacientes ortopédicos. Em S. M. Ismael (Org.), A prática psicológica e sua interface com as doenças (pp. 173-184). São Paulo: Casa do Psicólogo.

Giacomoni, C. H. (2002). Bem-estar subjetivo infantil: Conceito de felicidade e construção de instrumentos para avaliação. Tese de Doutorado, Universidade Federal do Rio Grande do Sul, Porto Alegre.

Gobbetti, G. J., \& Cohen, C. (2005). Bioética: desenvolvimento humano e os profissionais de saúde. Em S. M. Ismael (Org.), Temas de prevenção, ensino e pesquisa que permeiam o contexto hospitalar (pp.159-160). São Paulo: Casa do Psicólogo.

Ismael, S. M. (2005). Temas de prevenção, ensino e pesquisa que permeiam o contexto hospitalar. São Paulo: Casa do Psicólogo.

Lampropoulos, G. K. (2001). Integrating psychopathology, positive psychology, and psychotherapy. American Psychologist, 56, 87-88.

Libow, J. (1989). Chronic illness and family coping. New York: Guilford Press.

Masten, A. S., \& Garmezy, N. (1985). Risk, vulnerability and protective factors in developmental psychopathology. In B. B. Lahey \& A. E. Kazdin (Ed.), Advances in clinical child psychology (pp. 123137). New York: Plenum Press.
Morais, N. A., \& Koller, S. H. (2004). Abordagem ecológica do desenvolvimento humano, psicologia positiva e resiliência: Ênfase na saúde. Em S. H. Koller (Org.), Ecologia do desenvolvimento humano: Pesquisas e intervenção no Brasil (pp. 91-107). São Paulo: Casa do Psicólogo.

Pereira, A. M. S. (2001). Resiliência, personalidade, stress, e estratégias de coping. Em J. Tavares (Org.), Resiliência e educação (pp.77-94). São Paulo: Cortez.

Pesce, R., Assis, S. G., Santos, N., \& Oliveira, R. V. C. (2004). Risco e proteção: Em busca de um equilíbrio promotor de resiliência. Psicologia: Teoria e Pesquisa, 20 (2), 135-143.

Pinheiro, D. P. N. (2004). A resiliência em discussão. Psicologia em Estudo, 9, 67-75.

Rodrigues, A. L., \& Gasparine, A. C. L. F. (1992). Uma perspectiva psicossocial em psicossomática: Via estresse e trabalho. Em J. Mello Filho (Org.), Psicossomática hoje (pp. 93-107). Porto Alegre: Artes Médicas.

Romano, B. W. (1999). Princípios para a prática da psicologia clínica em hospitais. São Paulo: Casa do Psicólogo.

Rutter, M. (1993). Resilience: Some conceptual considerations. Journal of Adolescent Health, 14, 626-631.

Seligman, M. E. P., \& Csikszentmihalyi, M. (2000). Positive psychology: An introduction. American Psychologist, 55, 5-14.

Sheldon, K. M., \& King, L. (2001). Why positive psychology is necessary? American Psychologist, 56, 216-217.

Simon, R. (1989). Psicologia clínica preventiva: Novos fundamentos. São Paulo: EPU.

Trombeta, L. H. A. P., \& Guzzo, R. S. L. (2002). Enfrentando o cotidiano adverso - estudo sobre resiliência em adolescentes. Campinas: Alínea.

Yamamoto, K. (2005). Psicologia clínica preventiva. Em S. M. Ismael (Org.), Temas de prevenção, ensino e pesquisa que permeiam o contexto hospitalar (pp.13-31). São Paulo: Casa do Psicólogo. 


\section{Daniela Cristina Silva Bianchini}

Yunes, M. A. M. (2003). Psicologia positiva e resiliência: O foco no indivíduo e na família. Psicologia em Estudo, 8, 75-84.

Yunes, M. A. M., \& Szymanski, H. (2001). Resiliência: Noção, conceitos afins e considerações críticas. Em J. Tavares (Org.), Resiliência e educação (pp.13-42). São Paulo: Cortez. 